\title{
Knowledge and perception of Family Medicine among medical students at University of Ibadan, Nigeria
}

\author{
OE Fasola ${ }^{a}$ (D, AO Alao ${ }^{a}$, BA Ibisola ${ }^{a *}$ (D), AM Obimakinde $e^{a, b}$ and IC Odekunle \\ ${ }^{a}$ Department of Family Medicine, University College Hospital, Ibadan, Nigeria \\ ${ }^{b}$ Family Medicine Unit, Department of Community Medicine, University of Ibadan, Ibadan, Nigeria \\ *Corresponding author, Email: likitavabi2012@gmail.com
}

Background: Postgraduate training in Family Medicine in Nigeria began over three decades ago, but it was not until recently that the National University Commission (NUC) made it a policy for all Nigerian universities to include undergraduate Family Medicine training in their curriculum. This study aimed to assess the awareness and perception of Family Medicine among medical students at the University College Hospital (UCH), Ibadan.

Method: A descriptive cross-sectional study was conducted over a period of four weeks (June 11-July 6, 2018) among 131 fourth-year, 118 fifth-year and 163 sixth-year medical students at $\mathrm{UCH}$, Ibadan. Data were obtained using a self-administered questionnaire.

Results: Data were collected from 309 (75\% of the target population). The mean age of the respondents was $22.3 \pm 2.3$ years. The majority (74.4\%) did not have a family member who was a doctor and only $2.3 \%$ had a family member who was specialising in Family Medicine. Most of the participants (68.9\%) had good knowledge of Family Medicine, while $57.3 \%$ had good perception of Family Medicine as a specialty. Importantly, an increase in year of clerkship was associated with an increase in the knowledge of Family Medicine among the respondents.

Conclusion: It was observed that with increase in length of exposure to Family Medicine as a specialty, knowledge and perception of the specialty improved among the medical students. It is imperative that all the medical schools in Nigeria implement the NUC directive and start undergraduate Family Medicine training.

Keywords: knowledge, perception, Family Medicine, medical student, Ibadan

\section{Introduction}

The realisation of the essential role played by the family physician in the provision of quality first contact care and in the judicious use of limited resources has led to an increasing need for family physicians globally. ${ }^{1}$ Family physicians are specialist physicians trained to provide continued, comprehensive care for people of all ages irrespective of gender and illness; ${ }^{2}$ as such, it is important that more medical graduates choose to specialise in Family Medicine to facilitate efficient first contact care in all strata of healthcare delivery. ${ }^{1}$

Unfortunately, Family Medicine as a specialty still struggles for recognition in some parts of the world, especially in Africa, where a great need still exists in the teaching of Family Medicine at undergraduate level. ${ }^{3}$ The undergraduate teaching of Family Medicine may facilitate adequate and appropriate perceptions of the speciality by medical students and prevent incorrect bias against the speciality. In Nigeria, family physicians are sometimes perceived as being synonymous with medical officers, who are generalists with the basic medical degree and skills that are acquired from years of clinical practice without any structured postgraduate training or recertification. ${ }^{4}$ The core competencies that distinguishes a family physician from a medical officer include patient/person centred clinical methods (PCCM), using the biopsychosocial model of care, primary care management, specific problem-solving skills, a comprehensive approach and holistic modelling ${ }^{2}$ These competencies are best introduced early from the foundation years of medical school and should be ingrained in every doctor's basic medical training. This is currently lacking in the medical education obtained by most medical officers.
Though postgraduate family medicine training has been ongoing for up to 30 years in Nigeria, ${ }^{5}$ it is not reflective of inclusion of Family Medicine in undergraduate medical education. Unlike other specialties, which are introduced to medical students from the first year in medical school, undergraduate Family Medicine is yet to be fully incorporated into the curriculum of many medical schools in Africa. In Nigeria, despite the introduction of Family Medicine into undergraduate school at the University of Calabar, College of Medicine in $1976,{ }^{5,6}$ it is difficult to explain the slow adoption in other medical schools in Nigeria. Currently, only 15 universities, ${ }^{7,8}$ which equates to barely $1 \%$ of Nigerian medical schools, teach Family Medicine despite the 2015 recommendation by the National Universities Commission that Family Medicine should be incorporated into the undergraduate curriculum in Nigeria. ${ }^{9}$ In Europe, a study found that up to $19 \%$ of medical schools had no or a very brief Family Medicine curriculum. ${ }^{10}$ However, in South Africa, Family Medicine training is well established in most medical schools. ${ }^{3}$

According to the Nigeria Undergraduate Medical and Dental Curriculum template of $2012,{ }^{11}$ the tenets of Family Medicine should be introduced as part of lectures in the second and third years of medical school, while clinical rotations (clerkship) in Family Medicine I (Junior clerkship) and II (Senior clerkship) should be undertaken in the first semesters of the fifth and sixth years respectively. ${ }^{11}$ This is the format currently being utilised in the College of Medicine, University of Ibadan since 2015 following the implementation of the new integrated curriculum across all faculties of the university. ${ }^{12}$ Family Medicine lectures have also been newly incorporated into the core lectures 
series in the fourth year of medical education at the College of Medicine University of Ibadan.

In South Africa, a study across first- to fourth-year medical students showed poor knowledge across all groups of students, especially among first-year medical students. ${ }^{4}$ An improvement in knowledge of Family Medicine was noted among third-year Pakistani medical students who had a two-week clerkship in Family Medicine. ${ }^{13}$ Similar trends were reported among Spanish students following a four-month primary care course, inclusive of a one-week clinical clerkship in primary care. ${ }^{14} \mathrm{~A}$ systematic review by Turkeshi et al. in 2015 reported that learning experiences from clerkship tend to improve students' attitude and interest in the specialty and may influence their career intentions. ${ }^{15}$ Another study conducted in Saudi Arabia revealed that clinical rotations in Family Medicine improved the students' knowledge of and attitude to Family Medicine. ${ }^{16}$

As a specialty still in evolution globally, studies have shown a diverse variation in the length of clerkships and structure of undergraduate Family Medicine curriculum across different settings and in various countries. ${ }^{15}$ The teaching of Family Medicine is, however, yet to be incorporated into undergraduate medical education in most medical schools in Nigeria despite the National Universities Commission directive to create Family Medicine departments and allow for specific periods of Family Medicine didactic and clinical exposure. ${ }^{17}$ There is a paucity of information regarding Family Medicine teaching in medical schools in Nigeria. This study set out to determine the level of knowledge and perceptions of Family Medicine among medical students in Nigeria and the association with the length of clerkship.

\section{Methodology}

\section{Design and setting}

The study used a descriptive cross-sectional design and was conducted over a one-month period (June 11-July 6, 2018) at the University College Hospital (UCH), Ibadan located in Ibadan North Local Government Area of Oyo state. University College Hospital is an 850-bed hospital established in 1957 for the training of medical students at the College of Medicine, University of Ibadan (COMUI), resident doctors and other health professionals. The then Faculty of Medicine was one of the first faculties of the University of Ibadan at its establishment 68 years ago. Presently it is part of the COMUI, which is made of six faculties, namely the faculties of Basic Sciences, Clinical Sciences, Public Health, Dentistry, Nursing and Physiotherapy. ${ }^{18}$ The medical students are schooled within the Faculty of Basic Medical Sciences in the first three years of medical school and within the Faculty of Clinical Sciences in their last three years of the six-year programme of undergraduate medical training in Nigerian universities.

The first year until the end of the first half of the third year of medical school are preclinical in nature, while the latter half of the third year to the sixth year are clinical. It is noteworthy to explain that the second half of the third year is a transition phase when the students have general introductory lectures to clinical sciences and acclimatise to the clinical settings. The clinical years entail core lectures that span all organ/body systems, patient-centred care, community health, and laboratory medicine, as well as clinical rotations through the different clinical departments of University College Hospital (UCH), Ibadan.
The Family Medicine core lectures series consists of 22 didactic lectures spread over the first 18 months of the clinical years, which iterates Family Medicine tenets, perspectives and management of conditions across all organ systems. Two blocks of four-week clerkship rotations, namely Family Medicine I (junior clerkship) and Family Medicine (senior clerkship) II, are undertaken by the fifth- and sixth-year medical students in the Department of Family Medicine, UCH. The General Out-Patient Clinic (GOPC) of the Department of Family Medicine, UCH, Ibadan primarily serves as an entry point to the hospital for patients under the age of 60 years, while the Geriatric Centre, an off-shoot of the Family Medicine Department, cares for patients aged above 60 years. Patients in both the general outpatient clinic and geriatrics centre are seen, triaged and treated by Family Medicine resident doctors and consultant family physicians who provide primary and secondary levels of care and refer to other specialties as required. Students on Family Medicine clinical posting rotate through these two clinics.

\section{Study population}

The study involved medical students of the COMUI who were in the clinical school. There were 131 fourth-year students, 118 fifth-year students and 163 sixth-year students at the time of the study. The fourth-year (first clinical year) students were chosen to represent the baseline informants as they were yet to have Family Medicine clinical exposure. All consenting medical students in the fourth to sixth years who were present in the classroom at the time of data collection were included in the study.

\section{Data collection}

Data were collected using a self-administered questionnaire (Appendix 1), which contained different sections as follows:

Section A: Sociodemographic and family characteristics of the respondents.

Section B: Questions exploring the student's knowledge and understanding of Family Medicine as a specialty. The questions were derived from a pre-validated questionnaire from a similar study ${ }^{14}$ on the current undergraduate Family Medicine curriculum of the University of Ibadan. Each correct answer was scored 1 point, and an incorrect answer scored 0.

Section C: Questions on perception of the respondents towards Family Medicine, which was answered on a Likert scale: strongly agree, agree, uncertain, disagree and strongly disagree. The questions were derived from pre-validated questionnaires from similar studies assessing perception of Family Medicine among medical students ${ }^{14,19}$ and on anecdotal evidence on the perception of Family Medicine in this environment. Strong agreement and agreement with a positive statement on Family Medicine or strong disagreement and disagreement with a negative statement was scored 1 point. Any other response did not earn any points.

The survey was conducted in the classroom setting, either before or after class lectures. The study was explained to the medical students by a research assistant who had no affiliation with the medical students. The research assistant provided clarifications regarding the survey, obtained consent from the students and collected completed questionnaires. All questionnaires were anonymous and no personally identifiable information was collected. 


\section{Data analysis}

The primary outcome variables were knowledge and perceptions of Family Medicine. The independent variables were the sociodemographic characteristics. Knowledge and perception scores above the overall mean score of respondents were categorised as positive while those below the mean score were categorised as negative. Other variables were also grouped as categorical variables for ease of analysis. Data collected were cleaned and statistical analysis was performed using the Statistical Package for the Social Sciences (SPSS Version 20.0 IBM Corp, Armonk, NY, USA). The confidence interval was set to $95 \%$ and a $p$-value of less than 0.05 was considered significant. Descriptive statistics were displayed using frequency tables. Bivariate and multivariate analysis using a chi-square test and binary logistic regression respectively were carried out to test the association between sociodemographic characteristics and knowledge and perceptions of Family Medicine.

\section{Ethical considerations}

Approval of the Ethical Review Committee of the University of Ibadan/University College Hospital Ibadan Institutional Review Board (UI/UCH IRB) was obtained with study number UI/EC/18/ 0138.

\section{Results}

The results obtained from the data collected from 309 participants are presented in this section. The sociodemographic characteristics of the respondents are given in Table 1. Their mean age was $22.3 \pm 2.3$ years. Most of the respondents (74.4\%) did not have a family member who was a doctor, while only $2.3 \%$ had a family member who practices Family Medicine. The respondents' knowledge score ranged from 6 to 13 , with a mean score of $11.1 \pm 1.5$. The score for perception ranged from 0 to 14 with a mean score of $7.7 \pm 2.6$. As shown

Table 1: Frequency table of respondent sociodemographics

\begin{tabular}{|c|c|c|c|}
\hline \multicolumn{2}{|c|}{ Sociodemographic characteristics } & \multirow{2}{*}{$\frac{\text { Frequency }}{208}$} & \multirow{2}{*}{$\frac{\text { Percentage }}{67.3 \%}$} \\
\hline Gender & Male & & \\
\hline & Female & 101 & $32.7 \%$ \\
\hline \multirow[t]{2}{*}{ Age range } & $<25$ years & 272 & $88 \%$ \\
\hline & $>25$ years & 37 & $12 \%$ \\
\hline \multirow[t]{2}{*}{ Marital status } & Single & 306 & $99 \%$ \\
\hline & Married & 3 & $1 \%$ \\
\hline \multirow[t]{3}{*}{ Religion } & Christian & 263 & $85.1 \%$ \\
\hline & Islam & 37 & $12 \%$ \\
\hline & Others & 9 & $2.9 \%$ \\
\hline \multirow[t]{4}{*}{ Tribe } & Yoruba & 202 & $65.6 \%$ \\
\hline & Hausa & 5 & $1.6 \%$ \\
\hline & Igbo & 61 & $19.8 \%$ \\
\hline & Others & 40 & $13 \%$ \\
\hline \multirow[t]{3}{*}{ Year of clerkship } & Fourth year & 105 & $34 \%$ \\
\hline & Fifth year & 85 & $27.5 \%$ \\
\hline & Sixth year & 119 & $38.5 \%$ \\
\hline \multirow{3}{*}{$\begin{array}{l}\text { Medical doctor as } \\
\text { a family member }\end{array}$} & Family physician & 7 & $2.3 \%$ \\
\hline & $\begin{array}{l}\text { Specialist in } \\
\text { other specialties }\end{array}$ & 72 & $23.3 \%$ \\
\hline & None & 230 & $74.4 \%$ \\
\hline \multirow[t]{2}{*}{$\begin{array}{l}\text { Monthly } \\
\text { allowance }\end{array}$} & $\begin{array}{l}<\# 20,000 \\
(<\$ 55)\end{array}$ & 124 & $40.3 \%$ \\
\hline & $\begin{array}{l}\geq \# 20,000 \\
(\geq \$ 55)\end{array}$ & 184 & $59.7 \%$ \\
\hline
\end{tabular}

Table 2: Knowledge and perception of Family Medicine

\begin{tabular}{lcc}
\hline Variables & $\boldsymbol{n}=\mathbf{3 0 9}$ & Percentage \\
\hline Knowledge of Family & Medicine specialty: & \\
Positive & 213 & $68.9 \%$ \\
Negative & 96 & $31.1 \%$ \\
Perception of Family & \\
Positive & 177 & $57.3 \%$ \\
Negative & 132 & $42.7 \%$ \\
\hline
\end{tabular}

in Table 2, 68.9\% and $57.3 \%$ of the respondents had positive knowledge and a positive perception of Family Medicine as a specialty. Tables 3 and 4 show that as the clerkship year and monthly allowance increased, knowledge and perception of Family Medicine among the medical students also improved. A binary logistic regression performed to ascertain the effect of these factors showed that the monthly allowance was not

Table 3: Factors affecting knowledge of family medicine

\begin{tabular}{|c|c|c|c|c|}
\hline \multirow[b]{2}{*}{$\begin{array}{l}\text { Year of } \\
\text { clerkship }\end{array}$} & \multicolumn{2}{|c|}{ Knowledge of Family Medicine } & \multirow[b]{2}{*}{$x^{2}$} & \multirow[b]{2}{*}{$\begin{array}{c}p- \\
\text { value }\end{array}$} \\
\hline & $\begin{array}{c}\text { Negative } \\
\text { knowledge }\end{array}$ & $\begin{array}{c}\text { Positive } \\
\text { knowledge }\end{array}$ & & \\
\hline Fourth year & $52(49.5 \%)$ & $53(50.5 \%)$ & 26.562 & $.001^{*}$ \\
\hline Fifth year & $22(25.9 \%)$ & $63(74.1 \%)$ & & \\
\hline Sixth year & $22(18.5 \%)$ & 97 (81.5\%) & & \\
\hline \multicolumn{5}{|l|}{$\begin{array}{l}\text { Monthly } \\
\text { allowance }\end{array}$} \\
\hline $\begin{array}{l}<\$ 20,000 \\
(<\$ 55)\end{array}$ & $47(37.9 \%)$ & $77(62.1 \%)$ & 4.85 & $0.028^{*}$ \\
\hline $\begin{array}{l}\geq 20,000 \\
(\geq \$ 55)\end{array}$ & $48(26.1 \%)$ & $136(73.9 \%)$ & & \\
\hline
\end{tabular}

*Statistically significant at $5 \%$ level of significance.

Table 4: Factors affecting perception of Family Medicine

\begin{tabular}{|c|c|c|c|c|}
\hline \multirow[b]{2}{*}{$\begin{array}{l}\text { Year of } \\
\text { clerkship }\end{array}$} & \multicolumn{2}{|c|}{$\begin{array}{l}\text { Perception of Family Medicine } \\
\text { as a specialty }\end{array}$} & \multirow[b]{2}{*}{$x^{2}$} & \multirow[b]{2}{*}{$\begin{array}{c}p- \\
\text { value }\end{array}$} \\
\hline & $\begin{array}{c}\text { Negative } \\
\text { perception, } n \\
(\%)\end{array}$ & $\begin{array}{c}\text { Positive } \\
\text { perception, } n \\
\text { (\%) }\end{array}$ & & \\
\hline Fourth year & $55(52.4)$ & $50(47.6)$ & 6.371 & $.041^{*}$ \\
\hline Fifth year & $34(40.0)$ & $51(60.0)$ & & \\
\hline Sixth year & $43(36.1)$ & $76(63.9)$ & & \\
\hline \multicolumn{5}{|l|}{ Gender: } \\
\hline Male & $89(42.8)$ & $119(57.2)$ & 0.001 & 0.972 \\
\hline Female & $43(42.6)$ & $58(57.4)$ & & \\
\hline \multicolumn{5}{|l|}{$\begin{array}{l}\text { Doctor } \\
\text { family } \\
\text { member }\end{array}$} \\
\hline $\begin{array}{l}\text { Family } \\
\text { Medicine }\end{array}$ & $3(42.9)$ & $4(57.1)$ & 0.007 & 0.936 \\
\hline $\begin{array}{l}\text { Other } \\
\text { specialties }\end{array}$ & $32(44.4)$ & $40(55.6)$ & & \\
\hline \multicolumn{5}{|l|}{$\begin{array}{l}\text { Monthly } \\
\text { allowance }\end{array}$} \\
\hline $\begin{array}{l}<\# 20,000 \\
(<\$ 55)\end{array}$ & $63(50.8)$ & $61(49.2)$ & 5.356 & $.021 *$ \\
\hline $\begin{array}{l}\geq 20,000 \\
(\geq \$ 55)\end{array}$ & $69(37.5)$ & $115(62.5)$ & & \\
\hline
\end{tabular}

*Statistically significant at $5 \%$ level of significance. 
significantly associated with knowledge $(p=0.648)$ and perception $(p=0.12)$ levels respectively.

\section{Discussion}

This study showed that a significant number of medical students in the clinical years had a positive knowledge of Family Medicine as a specialty. The knowledge of Family Medicine is expected to be greater among those who have had higher levels of exposure to the practice as corroborated and reported by other studies. ${ }^{13}$ This was demonstrated by the increasing proportion of students with a positive knowledge of the specialty, which was elicited in $50 \%$ of the fourth-year students and in approximately $80 \%$ of the final-year students. The final-year (sixth year) medical students who had been exposed to a total of eight weeks of Family Medicine clerkship in addition to Family Medicine core lectures obviously demonstrated better knowledge of Family Medicine compared with the fifth-year medical students who had four weeks' clerkship and the fourth-year medical students who were yet to undergo a clinical clerkship posting in Family Medicine. This finding is similar to that of another study in which significantly higher scores were recorded for questions assessing knowledge in Family Medicine following a fourmonth Family Medicine course. ${ }^{14}$ In addition, exposure to a Family Medicine course and clerkships have been reported to improve attitudes to and perceptions of Family Medicine, as depicted in this study. ${ }^{14,16,19}$ In a study among students in a Spanish medical school, following a primary care course, there was a significant increase in the proportion of students who considered Family Medicine as a specialty of preference, increasing from $38.6 \%$ prevalence to $70.4 \% .{ }^{14} \mathrm{~A}$ higher monthly allowance was also found to be associated with better knowledge and perception of Family Medicine. This was most likely due to the confounding effect of their clerkship year as it is expected that the monthly allowance would increase with higher level classes in medical school based on their advanced needs. This study did not show a significant association between having a relation who is specialising in Family Medicine and medical students' perception of the specialty.

The drive to have family physicians in adequate numbers to cater for our population needs to be strategically entrenched through awareness creation at the undergraduate levels. The Nigerian Universities Commission has taken the first step by asking all universities in the country to commence Family Medicine training at the undergraduate level, a directive that is well embraced by the College of Medicine, University of Ibadan.

\section{Limitations}

This study was limited in that it was a cross-sectional study that could not establish a temporal relationship between clerkship exposure and changes in knowledge and perceptions of the students. This could have been achieved using a longitudinal study design; however, the mobility of clinical medical students especially for external elective posting would have made this challenging. In addition, this study could not include all students in clinical school as intended because of the exigencies of the medical school, which made some of the students unavailable at the time of data collection.

\section{Conclusion}

The result of this study shows that to improve the knowledge and perceptions of Family Medicine among medical students, clinical clerkship in Family Medicine should be promoted in medical schools. This is important because medical graduates with sound knowledge of Family Medicine, irrespective of future area of specialisation, will possess a good understanding of primary care, which will strengthen the healthcare systems of Nigeria as a nation.

\section{Recommendations}

The findings from this study support the National Universities Commission's recommendation that Family Medicine teaching and clinical clerkship must be included in the curriculum of medical schools in Nigeria.

Funding - The study received partial sponsorship from the Association of Resident Doctors (ARD), University College Hospital Ibadan 2017/18 Executive Year.

\section{Disclosure statement}

No potential conflict of interest was reported by the authors.

\section{ORCID}

OE Fasola (D) http://orcid.org/0000-0001-7384-1327

BA Ibisola (D) http://orcid.org/0000-0003-2763-2924

\section{References}

1. De Maeseneer J. Family Medicine facing new challenges on a global scale. In: The world book of Family Medicine. European. Ljubljana: Stichting WONCA Europe; 2015. p. 143-145.

2. Allen J, Gay B, Crebolder $\mathrm{H}$, et al. The European definition of general practice/ Family Medicine. 2011.

3. Besigye I, Mash R, Essuman A, et al. Conference report: undergraduate family medicine and primary care training in Sub-Saharan Africa: reflections of the PRIMAFAMED network. African J Prim Heal Care Fam Med ISSN Afr J Prm Heal Care Fam Med. 2017;9(1):2071-936.

4. Hagemeister D, Pal A, Naidoo N, et al. Undergraduate medical students' interest in specialising in Family Medicine at the University of the free state, 2014. South African Fam Pract. 2017;1(1):1-6.

5. Udonwa N, Ariba A, Yohanna S, et al. Family Medicine in West Africa: progress, milestones, and challenges so far in Nigeria (1980-2010). Niger J Fam Pr. 2011;1(2):1-9.

6. Okokon I, Ogbonna U, Asibong U, et al. Teaching family medicine in medical schools - The perspective from a Nigerian medical [Internet] University of Calabar. 2012 [cited 2017 Dec 27]. p. 1-11. Available from: https://www.researchgate.net/publication/266145778 Teaching family_medicine_in_medical_schools_-_The_perspective_from_a_ Nigerian_medical_school

7. Ladipo M. Undergraduate Family Medicine. In: 19th Annual General Meeting/Scientific Conference. Umuahia: Society of family physicians of Nigeria; 2016.

8. Society of family physicians of Nigeria. Update on status of undergraduate Family Medicine across Nigeria. In: 21st SOFPON Annua General Meeting. Akure: Society of family physicians of Nigeria; 2018. p. 6-7.

9. National Universities Commission. Implementing steps for new medical schools, accreditation issues and the new minimum benchmark (2015) for the MBBS/ BDS programmes [Internet]. Vol. 11, Monday Bulletin. Abuja; 2016. p. 20-1. Available from: http://nuc. edu.ng/wp-content/uploads/2015/01/MB-16th-May-2016-update. pdf

10. Brekke M, Carelli F, Zarbailov N, et al. Undergraduate medical education in general practice/family medicine throughout Europe-a descriptive study. BMC Med Educ. 2013;13(157):1-9.

11. Federal Ministry of Health of Nigeria HS 20/20 P. Nigeria undergraduate medical and dental curriculum template, 2012 [Internet] Bethesda, MD; 2012 [cited 2017 Jul 18]. p. 1-136. Available from: https://www.hfgproject.org/wp-content/uploads/2015/02/NigeriaUndergraduate-Medical-and-Dental-Curriculum-Template.pdf

12. Obimakinde A, llori T, Ladipo M. Undergraduate family medicine in nigeria: experience from the Premier University. In: 21st WONCA World Conference of Family Doctors. Rio de Janeiro: WONCA; 2016. 
13. Iqbal SP. Family medicine in undergraduate medical curriculum: a cost-effective approach to health care in Pakistan. J Ayub Med Coll Abbottabad. 2010;22(4):207-9.

14. Francisco ER, Jesus L-TH. Changes in the knowledge of and attitudes toward Family Medicine after completing a primary care course. Med Student Educ. 2010;42(1):35-40.

15. Turkeshi E, Michels NR, Hendrickx K, et al. Impact of family medicine clerkships in undergraduate medical education: a systematic review. BMJ Open. 2015;5:e008265.

16. Alyousefi NA. Knowledge and attitude of Saudi medical students towards the family medicine specialty during their family medicine course and its effect on their career plans: a comparative study Biomed Res. 2017;28(5):2256-61.

17. Chiedu J. NUC approves seven year, four year MBBS/BDS program in new minimum academic standards [Internet]. Medical World Nigeria. 2015 [cited 2017 Dec 27]. Available from: https://www.medicalworld nigeria.com/2015/11/nuc-approves-seven-year-four-year-mbbs-bdsprogram-in-new-minimum-academic-standards\#.WkPC-d-nHIU

18. University of Ibadan. History [Internet]. University of Ibadan. 2017 [cited 2017 Dec 28]. Available from: https://ui.edu.ng/History

19. Philips J, Charnley L. Third- and fourth- year medical students changing views of Family Medicine. Fam Med. 2016;48(1):54-60.

Received: 19-03-2019 Accepted: 23-07-2019

\section{Appendix 1}

\section{Questionnaire}

Knowledge and perceptions of Family Medicine among medical students at the University of Ibadan

Good day. This is a self-administered questionnaire for research purposes in Undergraduate Medical Education in Family Medicine conducted by a group of Family Medicine residents of the University College Hospital, Ibadan in collaboration with lecturers in the College of Medicine, University of Ibadan. Participation is voluntary and all information gathered will be treated as confidential. Thank you for agreeing to take part.

Signature:

Serial no:

\section{Section A: sociodemographic characteristics}

\begin{tabular}{|c|c|c|c|c|c|}
\hline 1. & 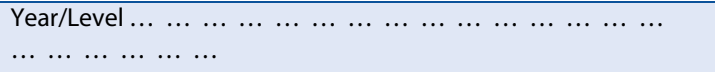 & & & & \\
\hline 2. & 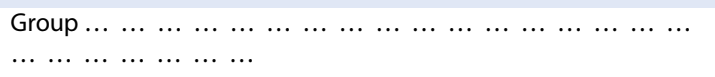 & & & & \\
\hline 3. & $\begin{array}{l}\text { Age as at last birthday (years) } \ldots \ldots \ldots \ldots \ldots \ldots \\
\ldots \ldots\end{array}$ & & & & \\
\hline 4. & Gender & 1. Male & 2. Female & & \\
\hline 5. & What position are you in the family & 1. First & 2. Last & 3. Others & \\
\hline 6. & Relationship status & 1. Single & 2. Engaged & 3. Married & \\
\hline 7. & Religion & 1. Christianity & 2. Islam & 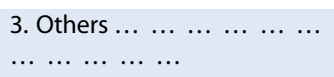 & \\
\hline 8. & Tribe & 1. Hausa & 2. Ibo & 3. Yoruba & $\begin{array}{l}\text { 4. Others } \ldots \ldots \\
\ldots \ldots \ldots \ldots\end{array}$ \\
\hline 9. & $\begin{array}{l}\text { What is your monthly monetary allowance from your parents/ } \\
\text { guardian? }\end{array}$ & $\begin{array}{l}\text { 1. Less than } \\
20,000\end{array}$ & $\begin{array}{l}\text { 2. } 20,000- \\
40,000\end{array}$ & 3. $40,000-60,000$ & $\begin{array}{l}\text { 4. } 60,000 \text { and } \\
\text { above }\end{array}$ \\
\hline 10. & 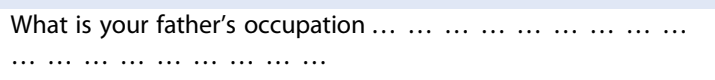 & & & & \\
\hline 11. & What is your father's highest level of education? & 1. None & 2. Primary & 3. Secondary & 4. Tertiary \\
\hline 12. & 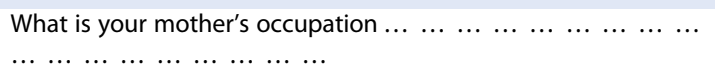 & & & & \\
\hline 13. & What is your mother's highest level of education? & 1. None & 2. Primary & 3. Secondary & 4. Tertiary \\
\hline 14. & Do you have any family member who is a medical doctor? & 1. Yes & 2. No & & \\
\hline 15. & If Yes to 14 above, what specialty? $\ldots \ldots \ldots \ldots \ldots \ldots \ldots \ldots$ & & & & \\
\hline 16. & How would you describe where you grew up? & 1. Rural & 2. Urban & & \\
\hline 17. & $\begin{array}{l}\text { How many degree exams have you written? (Part 1, Part } 2 \text { etc.) } \\
\begin{array}{lllllllllll}\ldots & \ldots & \ldots & \ldots & \ldots & \ldots & \ldots & \ldots & \ldots & \ldots & \ldots\end{array}\end{array}$ & & & & \\
\hline 18. & 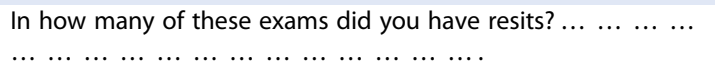 & & & & \\
\hline
\end{tabular}

\section{Section B: knowledge of Family Medicine specialty}

\begin{tabular}{llll}
\hline 20. & Family Medicine is a recognised specialty & 2. Yes \\
21. & Family physicians provide first-contact care and link patients to the healthcare system & 2. Yes \\
22. & Family physicians can manage people of all age groups & 2. Yes \\
23. & Family physicians can manage people irrespective of the disease & 2. Yes
\end{tabular}




\begin{tabular}{|c|c|c|c|}
\hline 24. & Family physicians provide comprehensive and continued care & 1. No & 2. Yes \\
\hline 25. & Family physicians manage problems that may not have a specific diagnosis & 1. No & 2. Yes \\
\hline 26. & Illness and disease are the same in Family Medicine & 1. No & 2. Yes \\
\hline 27. & Patient-centred care is emphasised in Family Medicine & 1. No & 2. Yes \\
\hline 28. & The family physician serves as an advocate for the patient and community & 1. No & 2. Yes \\
\hline 29. & The family physician is a researcher & 1. No & 2. Yes \\
\hline 30. & Family physicians are the same as general practitioners & 1. No & 2. Yes \\
\hline 31. & Family Medicine is the same as Internal Medicine & 1. No & 2. Yes \\
\hline 32. & Family Medicine is an important part of the health system & 1. No & 2. Yes \\
\hline
\end{tabular}

Section C: the following statements are on perceptions of family medicine. Please tick the box showing the response most appropriate to you

\begin{tabular}{l}
\hline 年 \\
\hline 33. Family Medicine clinical rotation is beneficial to medical students \\
34. I would rather have Family Medicine as an elective rather than compulsory rotation \\
35. The duration of the rotation is sufficient \\
36. Family Medicine is intellectually stimulating \\
37. The cases managed by family physicians are not serious cases \\
38. Family physicians are not as important as the other specialists \\
39. I do not think it is possible to be a specialist in Family Medicine as it covers a wide \\
range of medical problems \\
40. Family Medicine is easy compared with other specialties \\
41. I think there are more jobs for family physicians than other specialists \\
42. I think the workload in Family Medicine is more than in other specialties \\
43. I think other specialists make more money than family physicians \\
44. Cost of healthcare is reduced with more family physicians \\
45. I think the prospects for Family Medicine abroad are appealing \\
46. I think the prospects for Family Medicine in Nigeria are poor \\
47. I think Family Medicine is a specialty for females \\
\hline
\end{tabular}

